\title{
Rat Serum Contains a Developmentally Regulated Cholinergic Inducing Activity ${ }^{1}$
}

\author{
EVE J. WOLINSKY ${ }^{2}$ AND PAUL H. PATTERSON ${ }^{3}$ \\ Department of Neurobiology, Harvard Medical School, Boston, Massachusetts 02115
}

\begin{abstract}
Sympathetic neurons cultured in defined medium do not develop the ability to produce acetylcholine, as do neurons grown with serum supplementation (lacovitti, L., M. I. Johnson, T. H. Joh, and R. P. Bunge (1982) Neuroscience 7: 22252239; Wolinsky, E. J., S. C. Landis, and P. H. Patterson (1985) J. Neurosci. 5: 1497-1508). The implication that rat serum contains cholinergic inducing activity is further explored here. Dependence of cholinergic induction on serum concentration is demonstrated, and the activity is shown to reside in a macromolecular fraction. Very little cholinergic inducing activity is present in serum obtained from animals younger than 9 postnatal days. This age dependence correlates with the time of transition from noradrenergic to cholinergic transmitter status by the sympathetic innervation of the rat sweat gland in vivo (Landis, S. C., and D. Keefe (1983) Dev. Biol. 98: 349-372).
\end{abstract}

Comparison of neurotransmitter production by rat sympathetic neurons cultured with and without serum established that adult rat serum stimulates cholinergic development (Wolinsky et al., 1985). It is possible to ask whether this property of the serum changes during normal development, as a first step in determining whether it is related to development of cholinergic neurons of the sympathetic nervous system in vivo. During development of the sympathetic innervation of sweat glands in the footpads of rat hindlimb, a transition occurs in expression of transmitter-related properties, from noradrenergic to cholinergic (Landis and Keefe, 1983). During the first postnatal week, fibers approaching the immature sweat gland display catecholamine (CA) histofluorescence and do not display a detectable histochemical reaction for acetylcholinesterase. On the 10 th pustriatal day (P10), acetylcholinesterase staining appears, and

Received July 2, 1984; Revised October 5, 1984;

Accepted October 8, 1984

${ }^{1}$ This work was supported by grants from the National Institute of Neurological and Communicative Disorders and Stroke. E. J. W. was a predoctoral traince of the National Institute of General Medical Sciences. P. H. P. was a Rita Allen Foundation Fellow and a McKnight Foundation Neuroscience Development Awardee. Support was also provided by grants from the National Institute of Neurological and Communicative Disorders and Stroke to P. H. P. We would like to thank Doreen McDowell for assistance with the cell culturing. We also thank Drs. S. C. Landis and T. M. Jessell for holpful discussions of the manuscript.

${ }^{2}$ To whom correspondence should be sent, at her present address: Department of Biology, Massachusetts Institute of Technology, Cambridge, MA 02139.

${ }^{3}$ Present address: Division of Biology, California Institute of Technology, Pasadena, CA 91125.
CA fluorescence begins to decline. By the third postnatal week, cholinergic conversion is essentially complete. The view that a change of transmitter status occurs in individual axons, rather than replacement of the early noradrenergic innervation by cholinergic fibers originating from a separate population of neuronal cell bodies, is supported by the ability of chemical sympathectomy in neonates to prevent later appearance of cholinergic innervation (Yodlowski et al., 1984) and by the presence of axons of intermediate character (Landis and Keefe, 1983). One possible mechanism to bring about this transition is secretion of cholinergic inducing activity by the sweat gland at the time in development when functional innervation begins to occur.

In this report, the properties of the cholinergic inducing activity of rat serum are compared to those of the previously characterized factor in heart cell conditioned medium (Patterson and Chun, 1977; Fukada, 1980; Weber, 1981). The effect of the age of the animals from which the serum is obtained on its cholinergic inducing activity is examined, and the relevance of these results to the hypothesized role of targets in influencing development of cholinergic sympathetic neurons is discussed.

\section{Materials and Methods}

Cell culture. Serum-containing cultures were prepared from supcrior cer vical ganglia of newborn rats using enzymatic dissociation as described by Wolinsky and Patterson (1983). Serum-free cultures and N2L15 medium were prepared as described in the preceding paper (Wolinsky el al., 1985).

Metabolic labeling of acetylcholine (ACh) and CA. Isotopic incubation of living cultures with radiolabeled tyrosine and choline and high voltage electrophoretic separation of their metabolic products were performed as previously described (Mains and Patterson, 1973; Patterson and Chun, 1977; Wolinsky et al., 1985).

Rat serum preparation. Adult rat serum was prepared as previously described (Hawrot and Patterson, 1979) from sexually mature rats. Blood from younger animals was collected and processed similarly. Animals younger than 14 postnatal days (P14) were sacrificed by decapitation. In one experiment, serum was prepared from $\mathrm{P} 14$ animals killed by decapitation, and in another, $\mathrm{P} 16$ animals were killed by asphyxiation in a $\mathrm{CO}_{2}$ chamber, as were all adults from whom serum was obtained. Since both the P14 and P16 serum batches elicited cholinergic function (see "Results"), it is not likely that sacrifice by asphyxiation affects the cholinergic inducing activity of serum subsequently collected.

Serum fractionation. Adult rat serum ultrafiltrate was prepared by collecting the flowthrough from rat serum filtered on a UM2 Amicon Diaflo membrane $\left(M_{r}\right.$ cutoff $\left.=1000\right)$ under $40 \mathrm{psi}$ of nitrogen gas. Filtration was stopped when the material which did not pass through the filter had been concentrated 6 fold. The ultrafiltrate was sterilized by passage through a $0.2-\mu \mathrm{m}$ Millipore filter and stored in aliquots at $-20^{\circ} \mathrm{C}$. The serum concentrate was also stored in frozen aliquots and was filter sterilized after 125-fold dilution in N2L15 medium. Rat serum dialysate was prepared in Spectrapor tubing with a molecular weight cutoff of 6000 to 8000 . Dialysis of $8 \mathrm{ml}$ of adult serum was carried out at $4^{\circ} \mathrm{C}$ for $22 \mathrm{hr}$ against three changes of 2 -liter volumes of phosphate-buffered saline (prepared from Gibco 10-fold concentrate, calcium and magnesium free). The dialysate was filtered for sterility and aliquots were stored at $-20^{\circ} \mathrm{C}$.

Heart cell conditioned medium preparation. Serum-free heart cell condi- 
tioned medium (SFCM) was prepared by the method of Fukada (1980) and concentrated 10 -fold by ammonium sulfate precipitation as described by Weber (1981). Conditioned medium prepared with serum was made according to the method of Patterson and Chun (1977). Sister cultures of heart cells were incubated with either adult or neonatal serum at a concentration of $5 \%$, and all feedings and collections were performed at the same time for each flask.

\section{Results}

The relationship between transmitter status and the amount of adult rat serum present in the culture medium was determined by metabolic labeling of cultures grown in various serum concentrations. Cultures were incubated with $\left[{ }^{3} \mathrm{H}\right]$ choline and $\left[{ }^{3} \mathrm{H}\right]$ tyrosine (Patterson and Chun, 1977), and internal labeled stores of norepinephrine, dopamine, and ACh accumulated during isotopic incubation were separated by high voltage paper electrophoresis (Mains and Patterson, 1973). $\mathrm{CA}$ and $\mathrm{ACh}$ production are compared in Figure 1. Figure $1 A$ shows the ratio of these two quantities, a useful index of transmitter status, plotted against serum concentration. The ratio of ACh to CA production is linearly related to serum concentration up to a level of $10 \%$ and then appears to plateau. Similar batches of
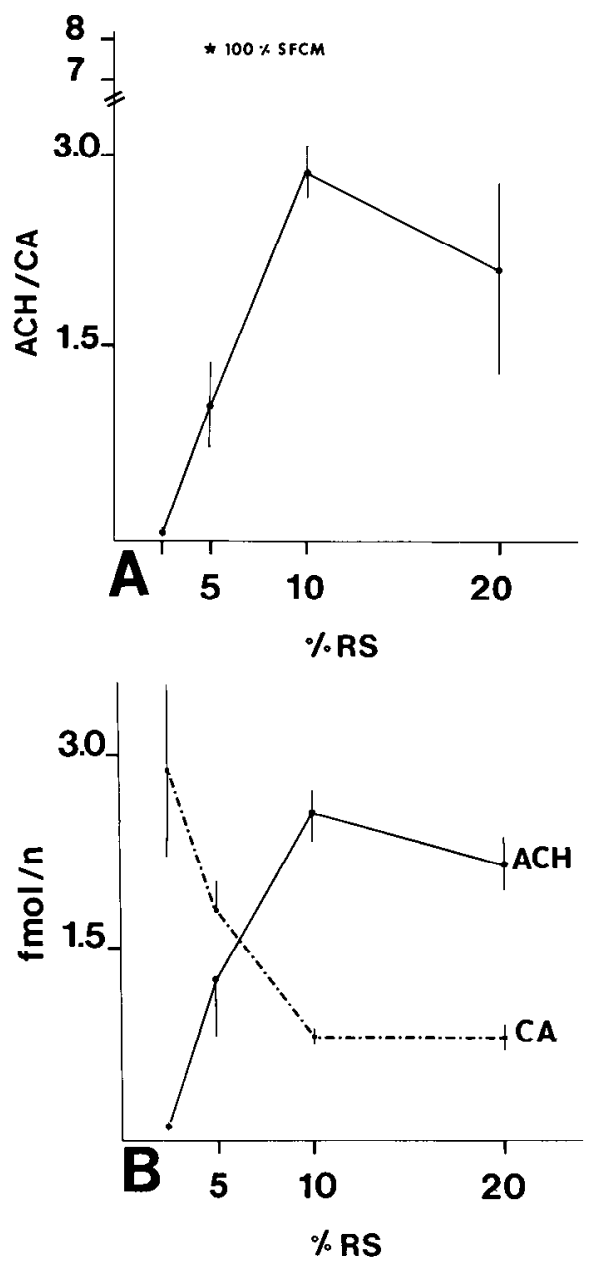

Figure 1. Effect of rat serum concentration on transmitter production. A shows mean \pm SE of the ratio of ACh to CA (sum of norepinephrine plus dopamine) production measured during metabolic labeling for three cultures grown in media containing each of the adult rat serum concentrations indicated. The asterisk shows the ACh to CA production ratio of a culture supplemented with heart cell conditioned medium factor as described in the text. Cultures were metabolically labeled at 3 weeks in vitro. $B$ shows data from the same experiment as in $A$. Production of ACh $(O)$ and $C A(\square)$ is shown in femtomoles per neuron. Points are graphed as mean $\pm S E$ for determinations made on three cultures, except for the $10 \%$ points, for which mean and range for two cultures are shown. serum caused serious toxicity at concentrations above $20 \%$; above this level, the effect of serum on transmitter production could not be determined. One exceptional serum lot induced a ratio of 10 -fold more production of ACh than of $\mathrm{CA}$ at a concentration of $30 \%$ without appearing to plateau.

The potency of the cholinergic inducing activity of rat serum is compared to that of heart cell conditioned medium in Figure $1 A$. Heart cell conditioned medium was prepared without serum, concentrated 10-fold, and diluted 10 -fold in culture medium for application to cultures at a dose equivalent to undiluted (100\%) preconcentration material. This treatment raised the level of $A C h$ production to nearly 8 -fold that of CA production. A dose of only $10 \%$ rat serum results in a ratio one-half to one-third of this value. Thus, were it not for the plateau in serum response (which may be due to toxicity), the serum lot tested in this experiment might be considered to be more effective than heart cell conditioned medium in inducing a changeover to more cholinergic transmitter status.

The effect of serum concentration on $C A$ and $A C h$ production individually is shown in Figure $1 B$. ACh production is increased in cultures maintained in higher concentrations of rat serum, and $C A$ production decreases concomitantly. These results are qualitatively similar to those of Patterson and Chun (1977), who showed that treatment with heart cell conditioned medium produced reciprocal effects on ACh and CA production. Thus, rat serum also appears to influence transmitter choice by suppression of noradrenergic function, as well as induction of cholinergic function.

The cholinergic inducing activity of heart cell conditioned medium resides in a protein of approximately 45,000 daltons (Weber, 1981). To determine whether the cholinergic inducing activity of rat serum is associated with high or low molecular weight components, various serum fractions were assayed for their effect on ACh production. Two types of macromolecular fractions were tested: dialysed rat serum, and material retained after ultrafiltration. The ultrafiltrate was used to assay low molecular weight components. Molecular weight cutoffs for the dialysis tubing and ultrafiltration membrane were 6000 to 8000 and 1000 , respectively. Due to the possibility that some of the above treatments might romove components essential for neu ronal survival, the serum preparations were tested in medium containing the ingredients of Bottenstein and Sato's (1979) N2 recipe, which is capable of supporting neuronal survival and differentiation in the absence of serum (Wolinsky et al., 1985). Figure 2 shows ACh production by cultures grown in various rat serum fractions. Each addition was adjusted to the volume equivalent of the amount present in medium containing $5 \%$ whole serum. Cultures supplemented with rat serum ultrafiltrate produced no more ACh than did cultures containing no serum components. However, dialysed rat serum, and material retained on an ultrafiltration membrane, elicited as much ACh production as whole rat serum. Thus, the cholinergic inducing activity of rat serum appears to have an $M_{r}>8000$.

It is of interest to determine whether the cholinergic inducing activity present in serum shows developmental regulation which might link it to the hypothesized factors acting in vivo. To test this possibility, serum was obtained from rats of various ages and used as a medium supplement at a concentration of $5 \%$. Metabolic labeling was used to measure transmitter production by cultures maintained in medium supplemented with these different sera. As illustrated in Figure 3, CA production was not affected by the age of the animals from which serum was obtained. However, neither serum from newborns nor that from week-old animals induced $\mathrm{ACh}$ production, whereas serum from 16-day-old animals had the same cholinergic inducing activity as adult serum. In a different experiment (data not shown), serum from 14-day-old animals also elicited ACh production. Thus, cholinergic inducing activity seems to appear in serum at between $\mathrm{P} 8$ and $\mathrm{P} 14$.

Secretion of cholinergic inducing activity by cultured heart cells is under hormonal control (Fukada, 1980). It is possible that the hypothesized developmentally regulated production of cholinergic inducing activity by appropriate target organs in vivo is also under 


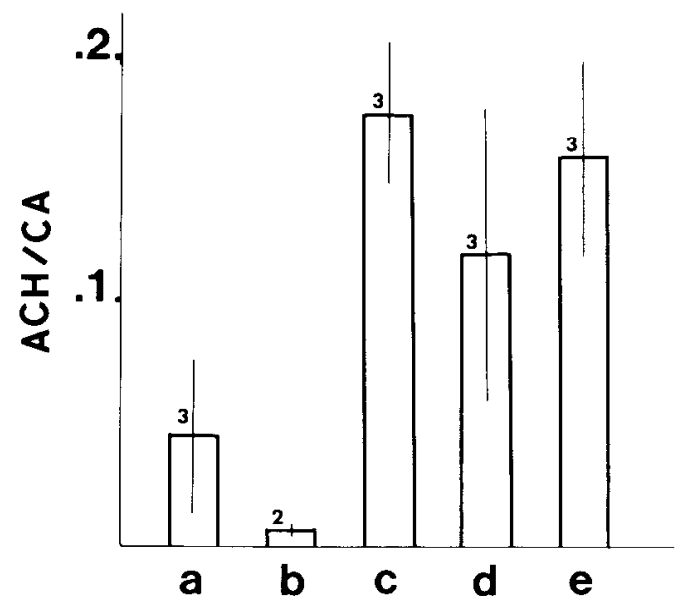

Figure 2. Effect of serum fractions on ACh production. ACh production in picomoles per culture determined by metabolic labeling is shown for cultures maintained in N2L15 medium with supplementation with different serum fractions as described in the text. Preparation of the serum fractions is described under "Materials and Methods." Data shown are mean \pm SE for determinations made on three cultures grown for 3 weeks with each type of supplement: (a) N2L15 without supplementation; (b) N2L15 with $5 \%$ rat serum ultrafiltrate; (c) N2L15 with $5 \%$ whole rat serum; (d) N2L15 with material retained during rat serum ultrafiltration (diluted with $\mathrm{N} 2 \mathrm{~L} 15$ to a concentration equivalent to $5 \%$ of its prefiltration volume); and (e) N2L15 with $5 \%$ dialysed rat serum.

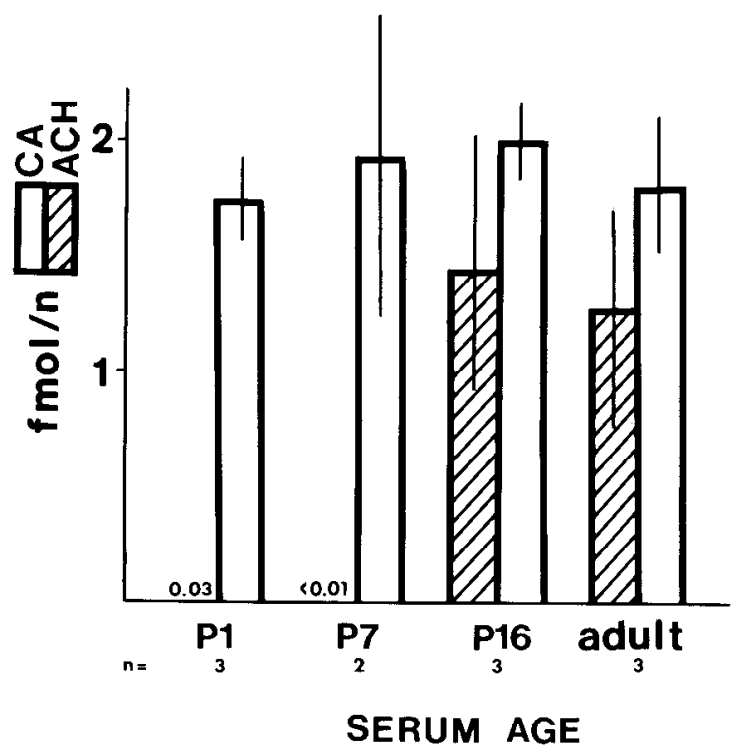

Figure 3. Effect of age of serum donors on transmitter choice. Production of ACh (hatched bars) and CA (sum of norepinephrine and dopamine; open bars) is shown in femtomoles per neuron as determined by metabolic labeling. The age of serum donors is indicated in postnatal days. The number of cultures used for each determination is indicated by $n$. Data shown are mean $\pm \operatorname{SE}(n=3)$ or mean and range $(n=2)$. Preparation of sera is described under "Materials and Methods." Cultures were metabolically labeled at 3 weeks in vitro.

hormonal control, and that the hormonal messenger is conveyed through the bloodstream. If this were the case, serum from neonates might not allow secretion of cholinergic inducing factor by cultured heart cells, since the necessary hormonal stimulus would not appoar in serum until cholinergic development was due to commence. The ability of adult serum and neonatal serum to allow secretion of cholinergic inducing factor by heart cells is compared in Table I. Neurons treated with conditioned medium prepared with either neonatal or adult serum produce more ACh and less CA than cultures grown without conditioned medium. Thus, although serum
TABLE I

Conditioned medium prepared with adult and neonatal sera Production of ACh and CA (sum of NE and DA) is shown in femtomoles per neuron (mean $\pm \mathrm{S}[$ ) as determined by metabolic labeling for three cultures grown under each condition for 2 weeks. " $5 \%$ RS" indicates cultures grown with adult rat serum and no conditioned medium. "RSCM" indicates heart cell conditioned medium prepared with adult rat serum, and "NNRSCM" indicates conditioned medium prepared with neonatal rat serum. The conditioned medium preparation is described under "Materials and Methods."

\begin{tabular}{lrcc}
\hline \multicolumn{1}{c}{ Medium } & \multicolumn{1}{c}{ CA/N $(\mathrm{fmol})$} & ACh/N $(\mathrm{fmol})$ & \multicolumn{1}{c}{ ACh/CA } \\
\hline $5 \%$ RS & $10.52 \pm 0.76$ & $0.06 \pm 0.03$ & $0.005 \pm 0.003$ \\
$5 \% \mathrm{RS}+50 \%$ RSCM & $5.22 \pm 1.55$ & $1.70 \pm 0.12$ & $0.35 \pm 0.07$ \\
$5 \% \mathrm{RS}+50 \%$ NNRSCM & $4.93 \pm 1.19$ & $2.51 \pm 0.63$ & $0.52 \pm 0.05$ \\
\hline
\end{tabular}

from newborn animals itself contains very little cholinergic inducing activity, it allows secretion of cholinergic inducing activity by cultured heart cells.

\section{Discussion}

The data reported here show that adult rat serum contains a developmentally regulated cholinergic inducing activity for cultured sympathetic neurons. The activity resides in the macromolecular fraction but has not been further charactcrized biochemically. The possible biochemical relationship of the serum activity to that of heart cell conditioned medium is not known. However, some comparisons can be made between the dose-response and other characteristics of these two sources of cholinergic induction. Cholinergic inducing activity from the two sources does not seem to have additive effects, since cultures grown without serum respond to the same dose of heart cell conditioned medium to the same extent as serum-containing sister cultures (Wolinsky et al., 1985).

The hypothesis that rat serum contains cholinergic inducing activity arose when transmitter production of serum-free and serum. containing cultures (both in the same basal medium, L15) was compared (Wolinsky et al., 1985) and serum-containing cultures were found to produce significantly more ACh than did serum-free cultures during metabolic labeling. lacovitti et al. (1982) also compared cholinergic function in serum-free and serum-supplemented cultures of rat sympathetic neurons and also observed a lack of cholinergic function in the absence of serum. These workers used human placental serum and chick embryo extract rather than homologous serum in their cultures. The possible effect of the hormonal supplement replacing rat serum in L15N2 medium on transmitter choice was assessed by combining rat serum with the N2 ingredients: no depression of ACh production was observed (Wolinsky et al., 1985). Thus, the cholinergic component of the dual-function phenotype of the serum-containing cultures used in our experiments is due to the presence of rat serum.

Soluble cholinergic inducing activity for cultured rat sympathetic neurons has been observed in culture supernatants of a number of primary rat tissues and rat cell lines (Patterson and Chun, 1977). A probable source of secreted cholinergic factor in primary cultures is fibroblasts, since the proportion of fibroblasts to myocytes increases with passaging, as does the potency of conditioned medium prepared from secondary cultures (Dr. K. Fukada, unpublished results). In addition, ganglionic non-neuronal cells grown in the presence of serum, which are largely fibroblasts, stimulate cholinergic function in co-cultures with neurons (Patterson and Chun, 1974), and both primary rat embryo fibroblasts and an embryo fibroblast cell line secrete cholinergic inducing activity (Patterson and Chun, 1977). Blood vosscl cpithelial cells are another possible source in primary cultures of rat tissues (Patterson and Chun, 1977). A factor which enhances cholinergic development of cultured chick ciliary ganglion neurons has also been found in embryonic eye extracts (Nishi and Berg, 1981). The cellular origin of the activity present in serum is not known.

Conditioned medium from heart cells is the most extensively 
characterized source of soluble cholinergic inducing activity. Both the heart cell conditioned medium and serum factors suppress noradrenergic development as well as inducing cholinergic properties. However, the suppression of CA production by rat serum shown in Figure $1 B$ is stronger than that observed for heart cell conditioned medium by Patterson and Chun (1977). A more quantitative comparison of levels of cholinergic inducing activity in rat serum and heart cell culture supernatant is hampered by the toxicity of rat serum at concentrations above $20 \%$ and by the variability in inducing activity between serum lots. An order of magnitude variation in ratio of ACh to CA production is seen between various platings of serumcontaining cultures $(\mathrm{ACh} / \mathrm{CA}=0.1$ to 1 ). Variability in serum lots may be a source of the different degrees of dual transmitter production seen in different platings of serum-containing cultures. The use of serum-free medium combined with heart cell conditioned medium may provide better control of the degree of dual function in cultured neurons.

The cholinergic inducing activity of heart cell conditioned medium is a medium-sized protein (Weber, 1981). However, small molecules, such as butyryl cyclic nucleotides, butyrate, and prostaglandin $E_{1}$, have also been found to affect transmitter choice (Walicke and Patterson, 1981). In addition, small molecules in serum have been found to affect growth characteristics of cultured cells (Ham, 1981), and $\beta$-adrenergic receptor sensitivity of 66 glioma cells was found to be affected by serum CA levels in culture (Dibner and Insel 1981). The size class of the cholinergic inducing activity of rat serum was determined by testing various serum fractions for their ability to promote development of $\mathrm{ACh}$ production in sympathetic neuron cultures. Serum ultrafiltrate containing molecules smaller than $M_{\mathrm{r}}=$ 1000 did not promote development of ACh production in this test, whereas serum dialysate containing molecules of $M_{r}>8000$ did. Thus, it appears that the cholinergic inducing activity of rat serum is macromolecular.

The most intriguing aspect of the serum cholinergic inducing activity reported here is its apparent developmental regulation. The timetable of cholinergic transition in the sweat gland described by Landis and Keefe (1983) is sirnilar to that of the appearance of cholinergic inducing activity in rat serum. However, the timetable of sympathetic cholinergic development at other end-organs may be different, and the similarity in timing between development of cholinergic innervation of sweat gland and serum cholinergic inducing activity may be fortuitous. It is also possible that neonatal serum inhibits response to cholinergic inducing factor, rather than lacking it. This can be tested by comparing the response to SFCM of cultures grown in adult and neonatal sera.

Possible hormonal regulation of the cholinergic inducing activity of rat serum is suggested by the observations of Fukada (1980), who found that glucocorticoid blocked and epidermal growth factor stimulated production of cholinergic inducing activity by cultured heart cells. This type of regulation might occur in vivo in normal development. Of possible relevance is the finding that glucocorticoid administration to pregnant rats prolongs expression of the transient adrenergic phenotype of fetal gut neurons (Jonakait et al., 1981). The effects of these hormones on development of sweat gland innervation in vivo will be of interest. Similarly, cholinergic inducing activity in serum from animals with modified hormone levels could be tested. It seems unlikely, however, that glucocorticoid levels in neonatal rat serum accounts for its lack of cholinergic inducing activity in culture. Cultured neurons do not respond directly to glucocorticoids (Fukada, 1980) and, evidently, the glucocorticoid concentration of neonatal serum is not adequate to block secretion of cholinergic inducing activity by cultured heart cells.

It is also not clear what role the cholinergic inducing activity of serum plays in the intact animal. If it is related to the differentiation of sympathetic cholinergic neurons, why would it be present in mature animals in which development is complete? An answer may lie in the possible plasticity of transmitter choice by adult sympathetic neurons (Wakshull et al., 1979; Potter et al., 1983), some of which can respond to heart cell conditioned medium when placed in culture. If transmitter choice remains even slightly malleable throughout life, stabilization of cholinergic function by appropriale target tissues may also be required throughout life. Another question is how cholinergic inducing activity enters serum, and whether this circulating factor affects neurons or other cells. One possibility is that the serum activity represents clearance from specific target tissues. The difficulty in interpreting the results reported here will only be resolved when the molecular basis of the interaction between targets and sympathetic neurons in cholinergic transition is better understood. Production of antibodies against cholinergic inducing factor from heart cell conditioned medium (Fukada, 1983) may provide the tools nceded to answer some of the questions raised here.

\section{References}

Bottenstein, J. E., and G. H. Sato (1979) Growth of a rat neuroblastoma line in serum-free supplemented medium. Proc. Natl. Acad. Sci. U. S. A. 76 : 514-517.

Dibner, M. D., and P. A. Insel (1981) Serum catecholamines desensitize betaadrenergic receptors of cultured C6 glioma cells. J. Biol. Chem. 256: 7343-7346.

Fukada, K. (1980) Hormonal control of neurotransmitter choice in sympathetic neuron cultures. Nature 287: 535-555.

Fukada, K. (1983) Studies on the cholinergic differentiation factor for sympathetic neurons. Soc. Neurosci. Abstr. 9: 614.

Ham, R. G. (1981) Survival and growth requirements of nontransformed cells. In Handbook of Experimental Pharmacology, R. Baserga, ed., Vol. 57, pp. 13-88, Spring-Verlag, New York.

Hawrot, E., and P. H. Patterson (1979) Long-term culture of dissociated sympathetic neurons. Methods Enzymol. 58: 574-584.

lacovitti, L., M. I. Johnson, T. H. Joh, and R. P. Bunge (1982) Biochemical and morphological characterization of sympathetics neurons grown in a chemically-defined medium. Neuroscience 7: 2225-2239.

Jonakait, G. M., M. C. Bohn, K. Markey, M. Goldstein, and I. Black (1981) Elevation of maternal glucocorticoid hormones alters neurntransmitter phenotypic expression in embryos. Dev. Biol. 88: 288-296.

Landis, S. C., and D. Keefe (1983) Evidence for neurotransmitter plasticity in vivo: Developmental changes in properties of cholinergic sympathetic neurons. Dev. Biol. 98: 349-372.

Mains, R. E., and P. H. Patterson (1973) Primary cultures of dissociated sympathetic neurons. I. Establishment of long-term growth in culture and studies of differentiated properties. J. Cell Biol. 59: 329-345.

Nishi, R., and D. K. Berg (1981) Two components from eye tissue that differentially stimulate the growth and development of ciliary ganglion neurons in cell culture. J. Neurosci. 1: 505-513.

Patterson, P. H., and L. L. Y. Chun (1974) The influence of non-neuronal cells on catecholamine and $\mathrm{ACh}$ synthesis and accumulation in cultures of dissociated sympathetic neurons. Proc. Natl. Acad. Sci. U. S. A. 71 : 3607-3610.

Patterson, P. H., and L. L. Y. Chun (1977) The induction of acetylcholine synthesis in primary cultures of dissociated rat sympathetic neurons. I. Effects of conditioned medium. Dev. Biol. 56: 263-280.

Potter, D. D., E. J. Furshpan, and S. C. Landis (1983) Transmitter status in cultured rat sympathetic neurons: Plasticity and multiple function. Fed. Proc. 42: 1626-1632.

Wakshull, E., M. I. Johnson, and H. Burton (1979) Postnatal rat sympathetic neurons in culture. II. Synaptic transmission by postnatal neurons. J. Neurobiol. 42: 1426-1436.

Walicke, P. A., and P. H. Patterson (1981) On the role of cyclic nucleotides in the transmitter choice made by cultured sympathetic neurons. J. Neurosci. 1: 333-342.

Weber, M. J. (1981) A diffusible factor responsible for the determination of cholinergic functions in cultured sympathetic neurons: Partial purification and characterization. J. Biol. Chem. 256: 3447-3453.

Wolinsky, E., and P. H. Patterson (1983) Tyrosine hydroxylasc activity decreases with induction of cholinergic properties in cultured sympathetic neurons. J. Neurosci. 3: 1495-1500.

Wolinsky, E. J., S. C. Landis, and P. H. Pattcrson (1985) Expression of noradrenergic and cholinergic traits by sympathetic neurons cultured without serum. J. Neurosci. 5: 1497-1508.

Yodlowski, M. L., J. R. Fredicu, and S. C. Landis (1984) Neonatal 6hydroxydopamine treatment eliminates cholinergic sympathetic innervation and induces sensory sprouting in rat sweat glands. J. Neurosci. 4: 15351548. 